\title{
Bilateral Complete-type Medial Discoid Meniscus
}

Gökçer UZER, Fatih YILDIZ, Mehmet Anıl PULATKAN, Nuh Mehmet ELMADAĞ'

Department of Orthopedics and Traumatology, Bezmialem Vakif University School of Medicine, İstanbul, Turkey

\section{ABSTRACT}

Discoid meniscus is an uncommon congenital anomaly, and it is rarely seen in the medial compartment of the knee. Literature about bilateral medial discoid meniscus pathology is also limited because one of the knees is usually asymptomatic, although the pathology bilaterally exists. The incidence of bilateral cases should be more than that in current literature because of a number of non-diagnosed cases. In this study, we discuss the approach for a patient with one-sided symptomatic bilateral medial discoid meniscus and present partial meniscectomy as a treatment method.

Keywords: Discoid meniscus, bilaterally, medial, complete

\section{Introduction}

The first study in literature about medial discoid meniscus, which is a quite uncommon anomaly, was published in 1941 by Cave and Staples (1). Studies about medial discoid meniscus are usually presented as case series (2-6). Because the anomaly cannot usually be seen on direct X-ray images and magnetic resonance imaging (MRI) or arthroscopy, which are generally applied as long as both knees are symptomatic, many patients with bilateral medial discoid meniscus may not be diagnosed (5). In this study, we present the case of a 16-year-old girl diagnosed with bilateral medial discoid meniscus pathology.

\section{Case Report}

A 16-year-old girl presented with left knee pain for 3 years, which had increased for the last 3 months. In the physical examination, her posteromedial joint line was painful with palpation and her medial McMurray and Apley tests were positive, while her lateral McMurray, Lachman, varus, and valgus stress tests were negative. The examination of the patellofemoral joint was also normal, and the joint was stable. Muscular atrophy was not detected. The pain increased during hyperflexion and complete extension of the knee. The Tegner Lysholm Knee Score was 11. Although direct X-ray images were normal (Figure 1), MRI of the left knee showed complete-type medial discoid meniscus with a horizontal tear (Figures 2a, b).

Although physical examination of the right knee was completely normal and the patient did not have any complaint for her right knee, MRI was obtained, and complete-type medial discoid meniscus was found in her asymptomatic right knee too (Figure 3). For the symptomatic left knee, saucerization as surgical treatment was planned. The consent of the patient was taken for the surgical treatment.

Under general anesthesia, anteromedial and anterolateral arthroscopy portals were used. The patellofemoral joint, lateral meniscus, medial and lateral femoral condyles, and medial and lateral tibial plateaus were arthroscopically normal. Partial medial meniscectomy (saucerization) was performed because the medial meniscus was completely discoid and a horizontal tear was observed (Figures 4a, b).Terminal extension exercises were started in the early postoperative period, and the 


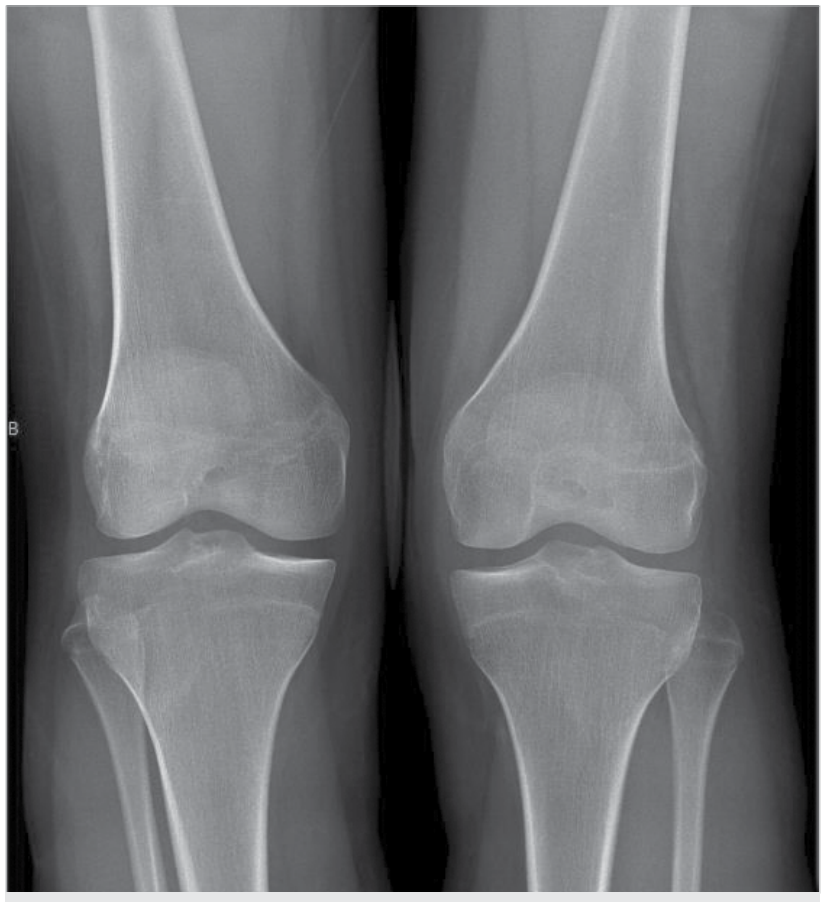

Figure 1. Both knees AP

patient was recommended to walk with full weight-bearing using crutches. A control MRI was performed 3 months postoperatively (Figure 5).

In the sixth month postoperatively, the patient was free of pain. Additionally, her medial McMurray and Apley tests were negative. The circumference of quadriceps muscles was measured at $5 \mathrm{~cm}$ proximal to the upper pole of the patellae and was found to be $33 \mathrm{~cm}$ and $34 \mathrm{~cm}$ in the left and right thigh, respectively. The postoperative Tegner Lysholm Knee Score was 67. In the first month of follow-up, the patient complained of right knee pain, which did not limiting her daily activities, in the medial joint line during hyperflexion of the knee. Her Apley and medial McMurray tests were positive, the knee joint was stable, and patellofemoral joint examination and muscle strength were normal.

\section{Discussion}

The etiology of the discoid meniscus has been explained in several ways; among them, one of the most supported theories is the embryonic explanation, which concerns the differentiation of the meniscus and anterior cruciate ligament from the same mesenchyme (7).

According to current literature, discoid meniscus pathology is usually seen in the lateral compartment of the knee, and it is rarely seen in the medial compartment $(2,5,8)$. In a prevalence study using MRI, only 7 of 14844 knees were diagnosed as having an isolated medial discoid meniscus pathology (2).

Dickason et al. (3) found the rate of medial discoid menis-
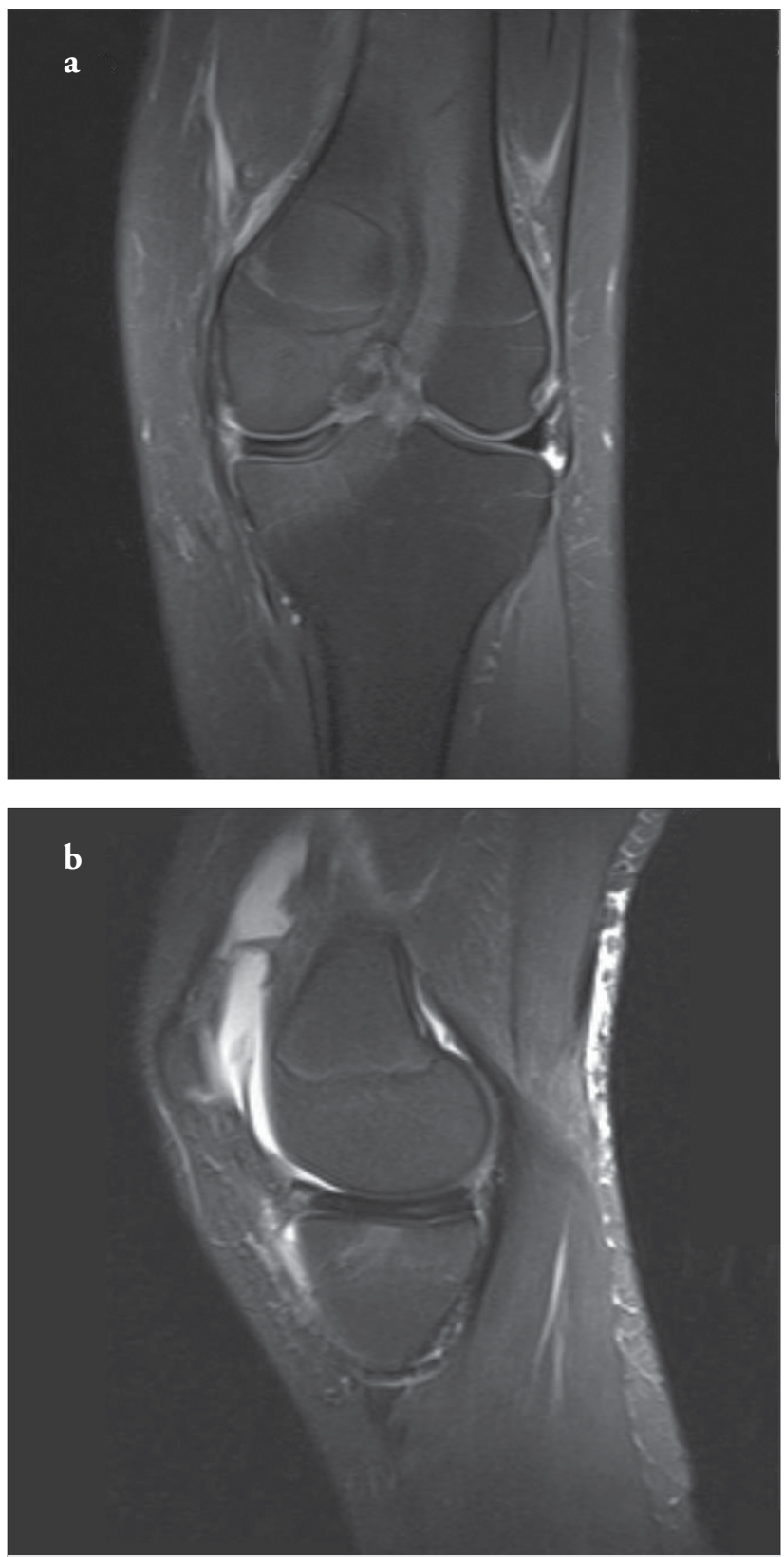

Figure 2. a, b. (a) Left knee preoperative coronal view MRI. (b) Left knee preoperative sagittal view MRI

Tachibana et al. (6) concluded in their MRI study that 5 of their 10 medial discoid meniscus cases were bilateral. Pınar et al. (5) reported their 6 complete and 3 incomplete types of bilateral discoid medial meniscus cases. In a study, more than 35000 medial meniscus cases were investigated, and medial discoid meniscus was found in only 32 knees (0.089\%) (2). The symptoms of medial discoid meniscus pathology, which are generally asymptomatic especially in children and adolescents, usually do not differ from the symptoms of meniscal tears. On physical examination, pain with medial joint line palpation, limited extension, popping, effusion in the joint, and positive McMurray test results can be found $(3,4,8)$.

Abnormal radiographic findings can be seen in only $10 \%$ of the patients (3). In anteroposterior radiographs, cupping of 


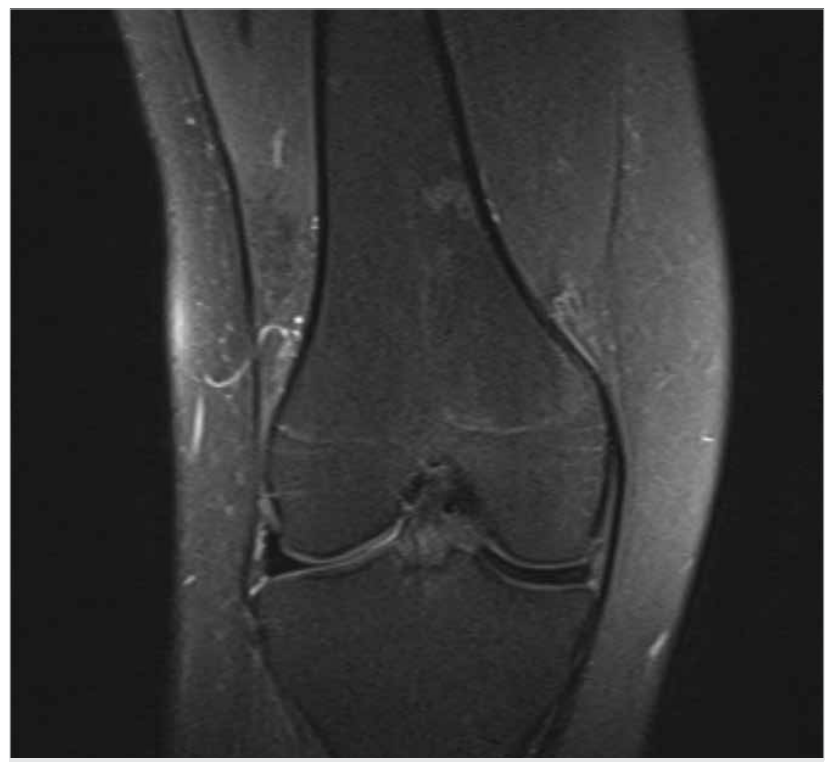

Figure 3. Right knee coronal view MRI

the medial tibial plateau, downfall of the proximal medial tibial physis (3), enlargement of the medial joint margin (1), and late degenerative joint disease $(2,3)$ can be seen. In our case, the X-ray images were completely normal in both knees (Figure 1).

Beside the fact that MRI is a technical choice for evaluation, it is also important to evaluate the morphology of the meniscus and degeneration or tear in the meniscus (9). In the diagnosis of discoid meniscus using MRI, continuity of the meniscal tissue between the anterior and posterior horns is important in the 3 sagittal sequential images (4).

A number of anomalies regarding medial discoid meniscus have been published, such as an abnormal insertion of the anterior horn of the medial meniscus into the anterior cruciate ligament, accompanying discoid lateral meniscus, meniscal cyst, and pathological medial patellar plicate (5). Our patient had an abnormal insertion of the anterior cruciate ligament into the anterior horn of complete-type medial discoid meniscus.

By means of routine MR imaging of the contralateral knee, it is seen that the rate of bilateral discoid meniscus pathology could be more than expected. A contralateral, asymptomatic knee may have discoid meniscus because the probability of symmetric meniscus is high (6).

Sixty percent of the cases are atraumatic and have increasing pain with accompanying swelling, locking, and snapping seen. Discoid medial meniscus cases are more prone to injuries than normal meniscus cases, and it is expected that these injuries will occur earlier than other meniscus lesions (2). This is the reason why patients with asymptomatic discoid meniscus pathology are recommended for activity modification (8).
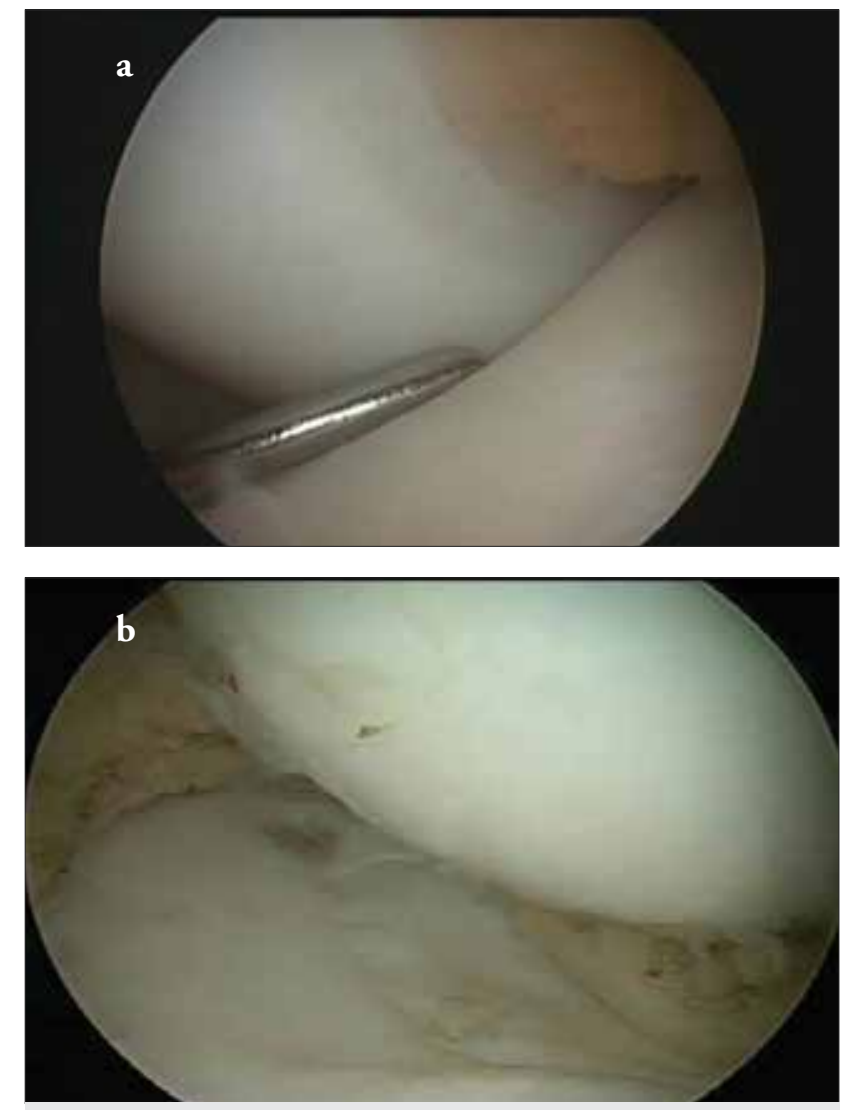

Figure 4. a, b. (a) Peroperative arthroscopic view of medial discoid meniscus. (b) Peroperative arthroscopic view after saucerization

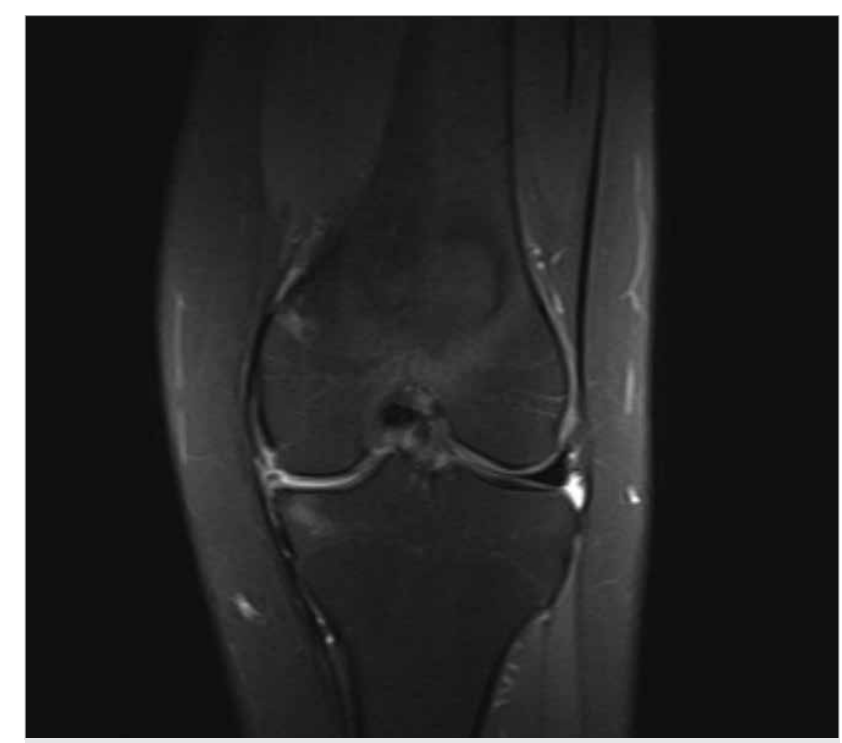

Figure 5. Left knee postoperative coronal view MRI

\section{Conclusion}

In this case, we observed that complaints of the patient due to discoid meniscus decreased after arthroscopic saucerization. From our point of view, it will be helpful for patients to be informed that this pathology may be bilateral and that surgical operation may not be needed as long as the contralateral 
knee is asymptomatic. Additionally, the degeneration of discoid meniscus occurs faster than that of a normal meniscus, and degeneration-related tears are more often seen in these cases; therefore, patients should be recommended to limit their sportive activities, if needed.

Informed Consent: Written informed consent was obtained from patient who participated in this case.

Peer-review: Externally peer-reviewed.

Author Contributions: Concept - G.U.; Design - G.U., M.A.P.; Supervision N.M.E., M.A.P.; Resources - G.U., N.M.E.; Materials - M.A.P., N.M.E.; Data Collection and/or Processing -M.A.P., F.Y.; Analysis and/or Interpretation - G.U., N.M.E., F.Y.; Literature Search - G.U., N.M.E.; Writing Manuscript - M.A.P., G.U.; Critical Review - G.U., N.M.E., F.Y.

Conflict of Interest: No conflict of interest was declared by the authors.

Financial Disclosure: The authors declared that this study has received no financial support.

\section{References}

1. Cave EF, Staples OS. Congenital discoid meniscus. A cause of internal derangement of the knee. Am J Surg 1941; 54: 371-6. [CrossRef]

2. Marchetti ME, Jones DC, Fischer DA, Boyd JL, Fritts HM. Bilateral discoid medial menisci of the knee. Am J Orthop (Belle Mead NJ) 2007; 36: 317-21.

3. Dickason JM, Del Pizzo W, Blazina ME, Fox JM, Friedman MJ, Snyder SJ. A series of ten discoid medial menisci. Clin Orthop Relat Res 1982; 168: 75-9. [CrossRef]

4. Blacksin MF, Greene B, Botelho G. Bilateral diskoid medial menisci diagnosed by magnetic resonance imaging: a case report. Clin Orthop Relat Res 1992; 285: 214-6. [CrossRef]

5. Pinar H, Akseki D, Karaoğlan O, Ozkan M, Uluç E. Bilateral discoid medial menisci. Arthroscopy 2000; 16: 96-101. [CrossRef]

6. Tachibana Y, Yamazaki Y, Ninomiya S. Discoid medial meniscus. Arthroscopy 2003; 19: E12-8. [CrossRef]

7. Min $\mathrm{BH}, \mathrm{Ha} \mathrm{HK}$, Khang SY. Medial discoid meniscus completely coalesced with the anterior cruciate ligament. Arthroscopy 2001; 17: E27. [CrossRef]

8. Kini SG, Walker P, Bruce W. Bilateral symptomatic discoid medial meniscus of the knee: a case report and review of literature. Arch Trauma Res 2015; 4: e27115. [CrossRef]

9. Dillon EH, Pope CF, Jokl P, Lynch K. The clinical significance of stage 2 meniscal abnormalities on magnetic resonance knee images. Magn Reson Imaging 1990; 8: 411-5. [CrossRef] 